\title{
Environmental Kuznets Curve and Income Inequality: Pooled Mean Group Estimation for Asian Developing Countries
}

\author{
Saif Ullah and Masood Sarwar Awan ${ }^{1}$
}

\begin{abstract}
Current study explores the association between environmental quality and economic growth along with role of income inequality within Environmental Kuznet Curve (EKC) framework by using three environmental quality variables (CO2, SO2 emission and PM2.5 concentration). The panel data of developing Asian countries have been employed for the investigation. Empirical analysis has been carried out by using PMG estimation technique. Results confirmed the presence of EKC for all environmental quality indicators for developing Asian economies in the long run. However, it does not hold in case of any environment quality indicator in the short run. Moreover, the findings reveal that income inequality is positively related to $\mathrm{CO} 2$, SO2 emission and PM2.5 concentrations. It indicates that rise in income inequality leads to increase CO2, SO2 emission and PM2.5 concentrations in the atmosphere. Furthermore, population density, urban population, foreign direct investment and trade openness are also positively related with all environmental quality variables.
\end{abstract}

Keywords: Environmental Quality, Income Inequality, EKC, PMG

JEL Classification: I3, Q53, O1, F31

\section{Introduction}

Last few decades have witnessed the evolution of term sustainable development and it gained more popularity among researchers. This term was first time explained by Brundtland commission report in 1987 as "Development that meets the needs of current generations without compromising the ability of future generations to meet their own needs" (WCED, 1987, p. 45). During the discussion of this term that will turn out in future it is important to consider the current and previous circumstances about environment and economy relationship. Sustainable Development is an all-inclusive approach which is surely the rightful successor of growth and development doctrine and key balancing lever, which may ensure

\footnotetext{
${ }^{1}$ The authors are Lecturer \& PhD Scholar and Professor \& Chairman at Department of Economics University of Sargodha, respectively. Corresponding author's mail: saifullah.zafar@uos.edu.pk
} 
equity across generations and various groups, is the environmental quality with its all allied linkages that proclaim the efficacy of sustainable development.

Ironically, recent past decades have observed that poor nations have experienced terrible obstacles in the way to get higher pace of economic development and industrialization without damaging the environmental assets and ecosystem. Research endeavors of the early 1990s produced empirical evidences which analyzed the environmental implications of different phases of economic growth. The Environmental Kuznets Curve (EKC) notion came into surface on the same analogy from ground-breaking research work of Simon Kuznets (1955) upon the correlative association of income inequality and per capita income known as Kuznets curve. Grossman and Krueger (1991) work provided the basis for the idea of EKC then it became agenda topic of researchers during 1990s. EKC theory narrates that during early stage of growth, that is, in the pre-industrial phase and/or in some time of industrial phase that needs more utilization of resources, there would have been an experience of increased level of environmental degradation leading to worsening environmental quality. However, in the later stages, that is, the remaining time frame of industrial phase and post-industrial phase, there would be successive improvement in environmental quality. Therefore, there hasn't been the situation of compromise on environment for all times and we do experience win-win situation in the later stages of economic growth.

There are two opinions regarding the explanation of EKC shape i.e. demand-side argument and supply-side argument in the literature. Regarding demand side strand, it is believed that with growth of income people would be more conscious about the environmental issues. On this pretext, we can say that after a certain benchmark in terms of income, people are more eager to pay for improved environment due to increase in income. Due to environmental issues, concerned people would pressurize firms and industries to use low emission production technologies and induce policy makers for inflexible environmental protection laws.

The supply-side argument was put forward by Grossman and Krueger (1995) at earliest place. He explained the idea by arguing in three ways. First is scale effect which is related to impact of expansion of economic activity on environment quality. It narrates that more natural resource consumption is needed for higher level of output which certainly correlates with higher emissions of gases leading to more environmental damage. Second argument known as composition or structural effect is associated with structural changes from agrarian to industrial based economy \& rural to urban within the economy. Technique effect posits 
advancement in technology and scientific progress. It is established that environment-friendly technologies are rooted in technique effect. Overall, the EKC proposition can be summarized into negative and positive effects of economic outcome on environment deterioration. Either it will be 'negative' in the earlier stages of growth during scale effect or 'positive' in later stages of growth as structural and technique effects became dominant over the scale effect.

Sustainable Development Goals (SDGs) also promoted the fight against inequality as one of its key messages because it hampers poverty reduction and growth. Kuznets (1955) affirmed urbanization and rural urban gap as major reasons of rising inequality and these are also reasons of deterioration of environment. It has also been established that environmental degradation and income inequality are interlinked strongly. Boyce (1994) addressed this issue at first place that rise in income inequality affects environment by the rich and poor people. The researchers have developed two different arguments about the influence of unequal income distribution on environment quality. Some are of the view that rise in income inequality improves environment quality while others conceive negative association between higher income inequality and environment degradation.

Many researchers have studied the incidence of EKC but only few have analyzed the role of unequal income distribution in EKC framework but for developed countries. These studies have used $\mathrm{CO}_{2}$ emission as pollution indicator using conventional panel data analysis methods which ignore the issue of heterogeneity. This study aims to remove the econometric drawbacks by adopting latest econometrics techniques of panel data analysis. The other studies related to EKC and role of inequality have been carried out at county level by employing time series data. These have limitations as time series data do not contain enough information and their findings may lead to incorrect policy implications. The current work also contributes in the existing literature by considering more environmental quality variables.

The current study has preferred developing Asian countries because of rising environmental deterioration trends in terms of higher $\mathrm{CO}_{2}$ emission, global warming and inequality since 1990 . Asian developing region has witnessed rapid growth rate and often known as growth center of world since last few decades but at same time gap between rich and poor has been rising than before contrast to other developing regions of world (Ota, 2017). So, it is important to encounter rising inequality for appropriate policy implications. On the basis of World Bank Atlas method 2018 these countries are declared as developing countries. Another reason for the selection of this region is that most of the MDGs targets were not fulfilled 
in these countries. Furthermore, association between environment quality and income inequality is unexplored for this region within the EKC framework. Thus, current study also attempts to fill the gap by including income inequality as an additional channel in explaining the relation between and environment degradation and economic growth. The remaining paper is arranged as; available literature is discussed in section two while section three consists of data and methodological explanation. Section four and five elaborates empirical findings and conclusion respectively.

\section{Literature Review}

There is bulk of literature available that has assessed the association between environment and per capita income at country level and regional level from many aspects but still few dimensions are not explored. There is some literature which focuses on role of income inequality within EKC framework. This section also presents review about EKC for different environment quality indicators.

Hailemariam et al. (2019) explored the relationship between environment quality and economic growth. The study also analyzed the impact of income inequality on environment quality for $17 \mathrm{OECD}$ countries. It employed data ranging from 1945 to 2010 gathered from Oak Ridge National Laboratory (ORNL) Information Analysis Centre, Maddison Project database and Madsen et al. (2018) Income Database. The study employed CCEMG estimators, FMOLS and DOLS techniques for empirical estimations. The findings indicated positive and significant association between income inequality and $\mathrm{CO}_{2}$ emission. In addition, study found positive and significant influence of GDP per capita and negative effect of GDP per capita square on $\mathrm{CO}_{2}$ emission verifying the evidence of $\mathrm{EKC}$ for OECD countries.

Hao et al. (2016) used Chinese provincial level data to investigate the influence of income inequality on environment quality. The study used Gini coefficient and per capita growth as measures of income inequality and per capita income respectively. GMM technique has been used for empirical investigations because it deals with the issue of endogeneity. The results concluded that income inequality exerted negative impact on per capita growth in all provinces. The findings also verified the existence of inverted U-shape relationship between per capita growth and $\mathrm{CO}_{2}$ emission.

Borghesi, (2006) explored the effect of unequal income distribution on environment degradation within the EKC framework for 126 countries during the 
period 1988-1995. The study estimated two regression equations with and without income inequality by employing different specification. The study employed different functional specification to analyze the correlation by utilizing panel data retrieved from WDI dataset. The study also adopted different estimation tools such as pooled OLS and fixed effect model. Both techniques provided different findings. Income inequality exerted negative impact on $\mathrm{CO}_{2}$ emission which implied that rise in inequality reduces $\mathrm{CO}_{2}$ emission while exerted positive effect in fixed effect model. The effect of inequality remained statistically insignificant in case of both techniques. Moreover, analysis was also carried out separately for rich and poor countries to make appropriate suggestions. The finding suggested that income inequality decreases emission in the high-income countries and leads to increase in the low-income countries. The other explanatory variables which includes population density industry value added share were positively associated with $\mathrm{CO}_{2}$ emission.

Demir et al. (2019) analyzed the association between economic growth, income inequality and environment quality for Turkey. The study employed time series data ranging from 1963 to 2011 and carried out empirical analysis by using ARDL approach. The findings depicted that income inequality has negative impact on economic growth meaning that rise in income inequality reduces $\mathrm{CO}_{2}$ emission in Turkey. Moreover, results indicated that EKC holds for Turkey.

Ravallion et al. (2000) estimated regression equation to analyze the income inequality and pollution relationship by using $\mathrm{CO}_{2}$ emissions as pollution indicator. The study used data for 42 countries during the period 1975 to 1992. Parameters had been estimated first by utilizing fixed effect model and then with pooled OLS. The results concluded negative correlation between carbon emissions and inequality within countries. However, at higher average incomes the effect of income distribution on the environment decreases.

Masud et al. (2018) employed panel data from 1985 to 2015 to explore the causality between environmental sustainability and income inequality for five ASEAN countries. The analysis was carried out by employing panel granger causality and generalized least squares (GLS). The results posited that environmental sustainability cause income inequality while there was no evidence of cause from income inequality to environmental sustainability. Moreover, GLS results showed positive and significant correlation between income inequality and $\mathrm{CO}_{2}$ emission.

Serrano et al. (2015) examined the effect of income inequality on environmental degradation for 26 Brazilian states by applying pooled OLS, fixed 
effect and random effect models to. The study employed panel data from 1990 to 2008 for analysis. Institute of Applied Economic Research data were used for empirical analysis. The empirical estimates have been obtained by using three models and applying different econometrics techniques. The results found that income inequality has no impact on environmental degradation in any model.

Clement and Meunie, (2010) analyzed the relationship between environmental degradation and income inequality by employing panel data from 1988 to 2003 for 67 developing and 16 transition countries. The study used SO2 Emission and BOD for pollution and GINI index to represent inequalities. The data were taken from ASL database and WDI 2007. The random effect model and fixed effect model were employed for econometric analysis and study found that rise in income inequality does not increases $\mathrm{SO}_{2}$ emission, but water pollution rises for developing and transition economies.

Torras and Boyce, (1998) examined the impact of unequal income distribution on pollution measures except $\mathrm{CO}_{2}$ emission for high- and low-income countries. The study used seven pollution measures as dependent variable obtained from Global Environment Monitoring System dataset (GEMS) and per capita income, urbanization, literacy rate and political rights as explanatory variables. On the environmental impact of income inequality, they found mixed results with OLS estimation. The effect of income inequality is positive for some water and air pollution measures and negative for some other indicators. The effect of Gini coefficient on $\mathrm{SO}_{2}$ is positive for low income countries implying that rise in inequality increases $\mathrm{SO}_{2}$ emission for low income countries and negative for high income group posing income inequality improve environment quality.

\section{Data and Methodology}

\subsection{Model Specification}

It is obvious from literature that researchers have used linear, log linear and $\log$-log specifications for the analysis of EKC. The studies also differ in case of degree of per capita GDP used in regression equation. However, all the specifications have merits and demerits but use of log-log specification has advantage for the analysis of income environment relationship especially in case of panel data (Perman and Stern, 2003). The selection of functional form and variables has been made after taking into account Drabu (2011), Borghesi (2000) and Masud et al. (2018) to examine the relationship among environment quality indicators, per capita income and income inequality. 


\section{Model 1}

$$
\begin{aligned}
& \text { LnCO } C_{2 i t}=\alpha_{0}+\alpha_{1} L n G D P P C_{i t}+\alpha_{2} L_{n G D P P C S}+\alpha_{3} L_{i n} I N E Q_{i t}+\alpha_{4} L n P D_{i t}+ \\
& \alpha_{5} L_{n U P}+\alpha_{6} \operatorname{LnFDI}_{i t}+\alpha_{7} \operatorname{LnTO}_{i t}+\varepsilon_{i t}
\end{aligned}
$$

\section{Model 2}

$$
\begin{aligned}
& \text { LnSO }_{2 i t}=\beta_{0}+\beta_{1} L n G D P P C_{i t}+\beta_{2} L n G D P P C S_{i t}+\beta_{3} L n I N E Q_{i t}+\beta_{4} L n P D_{i t}+ \\
& \beta_{5} L n U P_{i t}+\beta_{6} L_{n F D I}+\beta_{7} L_{i n T O}+v_{i t}
\end{aligned}
$$

\section{Model 3}

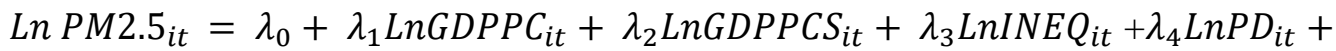
$\lambda_{5} L n U P_{i t}+\lambda_{6} L n F D I_{i t}+\lambda_{7} L_{n T O} O_{i t}+\mu_{i t}$

Ln depicts natural logarithm whereas $\mathrm{i}=1, \ldots, 16$ and $\mathrm{t}=1973, \ldots \ldots, 2016$ indicate countries and time periods for model 1 and $\varepsilon_{i t}, v_{i t}$ and $\mu_{i t}$ are error terms of the models. Model 2 and 3 employs data from 1973 to 2010 based on the availability of data. Carbon Dioxide $\left(\mathrm{CO}_{2}\right)$ emission, Sulphur Dioxide $\left(\mathrm{SO}_{2}\right)$ emission and Particulate Matter (PM2.5) concentration have been used as environment quality indicators. The Particulate are combination of different liquid droplets and solid matters hanging in the atmosphere. The size of particulate matters varies from 2.5 to 10 micrometers $(\mathrm{PM} 2.5 \mu \mathrm{m}-\mathrm{PM} 10 \mu \mathrm{m})$ and these are categories into Coarse (PM10), Fine (PM2.5) and Ultrafine (PM0.1) particles on the basis of size and composition. The current study focuses on the PM2.5 known as fine particles because these are tiny in size and can stay for longer time in atmosphere. Fine particles affect human health through breathing. It will ultimately reduce economic activity due to fall in labor supply and productivity. The higher value of $\mathrm{CO} 2, \mathrm{SO} 2$ emission and PM2.5 in air indicate more environmental degradation showing poor environmental quality and vice versa. $\mathrm{SO}_{2}$ emission gigagram $(\mathrm{Gg})$ and $\mathrm{PM} 2.5$ gigagram $(\mathrm{Gg})$ data were collected from European Commission, Joint Research Centre (JRC)/PBL Netherlands Environmental Assessment Agency database. GDPPC and GDPPCS represents gross domestic per capita as a proxy of economic growth and square of gross domestic product per capita measured in constant 2010 US dollars are used to analyze the existence of EKC. INEQ denotes income inequality captured by Gini index and its data is retrieved from Standardized World Income Inequality Database (SWIID2016) developed by Solt (2009). The SWIID data is considered better than World Income Inequality Database (WIID) due to greater coverage and more comparability. PD is population density measured per square $\mathrm{km}$ of land and UP denotes urban population captured as percentage of urban 
population. These both variables have been taken into account to measure demographic characteristics of the countries. Economic openness is captured by foreign direct investment (FDI) calculated as percentage of FDI inflows to GDP and trade openness (TO) calculated as exports plus import percentage of GDP. The effect of FDI on environment quality depends upon three effects which are scale effect, technique effect (tech) and composition effect. The data of all economic, demographic variables and $\mathrm{CO} 2$ emission metric tons per capita have been obtained from the World Bank World Development Indicator (WDI 2018).

\subsection{Levin-Lin-Chu Test (2002)}

LLC test is applicable in balanced panel which assumes that autoregressive coefficients to be uniform for entire panel. $H_{0}=\rho_{i}=0$ for all $i$ is null hypothesis of LLC. Levin et al. (2002) is basically panel expansion of ADF test and is constructed on following ADF type regression:

$$
\Delta P_{i t}=\rho_{i} P_{i, t-1}+\sum_{j=1}^{q_{i}} \alpha_{i j} \Delta P_{i, t-j}+\phi Z_{i t}+\varepsilon_{i t}
$$

The lag order qi is used for differenced term and it is allowed to differ across individuals. It is used to resolve the issue of residuals correlation. $\mathrm{P}_{i t}$ represents every variable to be tested for stationary. $Z_{i t}$ is deterministic component and may be fixed effect or time trend. The test has 3 steps procedure. In first step above regression equation is estimated for every cross-section in the panel. In second step, the residuals are obtained from the two following auxiliary regressions:

$\hat{e}_{i t}=\Delta P_{i t}-\sum_{j=1}^{q_{i}} \hat{\pi}_{i j} \alpha_{i j} \Delta P_{i, t-j}-\varphi \hat{Z}_{i t}$

$\hat{v}_{i, t-1}=P_{i, t-1}-\sum_{j=1}^{q_{i}} \tilde{\pi}_{i j} \alpha_{i j} \Delta P_{i, t-j}-\varphi \hat{Z}_{i t}$

The residuals are then weighted by the regression standard error to control for heterogeneity across cross sections, becoming $\tilde{e}_{i t}$ and $\tilde{v}_{i, t-1}$.

$\tilde{e}_{i t}=\frac{\hat{e}_{i t}}{\hat{\sigma} \varepsilon_{i}}$

$\tilde{v}_{i, t-1}=\frac{\hat{v}_{i, t-1}}{\hat{\sigma} \varepsilon_{i}}$

Each ADF regression standard error is computed which is represented by $\hat{\sigma}$. Lastly, pooled OLS regression is run on $\tilde{e}_{i t}=\rho \tilde{v}_{i, t-1}+\tilde{\varepsilon}_{i t}$ to compute pooled t- 
statistic. Finally, it is compared with table values for possible acceptance and rejection of null hypothesis.

\subsection{Im, Pesaran and Shin (IPS) (2003) tests}

LLC test has some drawbacks as it assume cross sectional independence and is not applicable in case of presence of serial correlation among the residuals across cross sectional units. The major improvement of IPS is its alternative hypothesis that allows autoregressive coefficient to be different for different cross sections. The basic equation of IPS can be written as:

$$
\Delta P_{i t}=\alpha_{i}+\rho_{i} P_{i, t-1}+\sum_{j=1}^{q_{i}} \delta_{i j} \Delta P_{i, t-j}+\varepsilon_{i t}
$$

$\mathrm{P}_{\mathrm{it}}$ represents every variable under consideration, individual or fixed effect is denoted by $\alpha_{i}$ and $\mathrm{q}_{\mathrm{i}}$ is lagged term used to solve overtime residuals correlation issue. The null hypothesis is $H_{0}=\rho_{i}=0$ for all $i$ Against the alternatives $\rho_{i}<0$ for $i=1,2,3 \ldots . ., N_{1}$ and $\rho_{i}=0$ for $i=N_{1}+1, N_{1}+2 \ldots ., N$. It allows for some (but not all) of individual series to have unit roots. They formulated a $t$-bar statistic, which is computed by taking average of the individual ADF test statistics. Its formula is written as:

$\bar{t}=\frac{1}{N} \sum_{i=1}^{n} t_{i T}$

t-statistics for each country $\mathrm{i}$ is denoted by $\mathrm{t}_{\mathrm{i}}$ computed from ADF regression for testing $\rho_{i}=0$. If this statistic is properly standardized, it is asymptotically $\mathrm{N}(0,1)$ distributed. The standardized IPS t-bar statistic is given by:

$$
t_{I P S}=\frac{\sqrt{N}\left(\bar{t}-1 / N \sum_{i=1}^{N} E\left[t_{i t} / \rho_{i}=0\right]\right)}{\sqrt{N^{-1} \sum_{i=1}^{N} \operatorname{var}\left[t_{i t} / \rho_{i}=0\right]}}
$$

\subsection{Pedroni Tests (2004)}

Pedroni (1995) introduced the first residual-based panel cointegration test. Pedroni (1999) and (2004) are panel expansion of Engle and Granger (1987) test with more than one explanatory variable in the regression equation. The test allows slope coefficients to be different across cross sectional units and allows 
heterogeneity in the cointegration vector. Pedroni introduced seven cointegration tests on the basis of residuals with null hypothesis of no cointegration. First four tests cover within dimension effect of panel and are known as panel statistic while three tests cover between dimension effects of panel and recognized as group statistics. The most important characteristic of these statistics is that they are based on common process and also known as within dimension tests. On other hand remaining three tests are based on individual process and known as group panel statistics or between dimension tests. Pedroni defines the seven following statistics:

$$
\begin{aligned}
& \text { Panel v-statistics }: Z_{v}=\left(\sum_{i=1}^{N} \sum_{t=1}^{T} R_{11 i}^{-2} \hat{e}_{i t-1}^{2}\right)^{-1} \\
& \text { Panel } \rho \text {-statistics }: Z_{\rho}=\left(\sum_{i=1}^{N} \sum_{t=1}^{T} R_{11 i}^{-2} \hat{e}_{i t-1}^{2}\right)^{-1} \sum_{i=1}^{N} \sum_{t=1}^{T} R_{11 i}^{-2}\left(\hat{e}_{i t-1} \Delta \hat{e}_{i t}-\lambda_{i}\right) \\
& \text { Panel PP-statistics(Non Parametric) }: Z_{t}=\left(\sigma^{2} \sum_{i=1}^{N} \sum_{t=1}^{T} R_{11 i}^{-2} \hat{e}_{i t-1}^{2}\right)^{-1 / 2} \sum_{i=1}^{N} \sum_{t=1}^{T} R_{11 i}^{-2}\left(\hat{e}_{i t-1} \Delta \hat{e}_{i t}-\lambda_{i}\right) \\
& \text { Panel ADF-statistics(Parametric) }: Z_{t}^{*}=\left(s^{* 2} \sum_{i=1}^{N} \sum_{t=1}^{T} R_{11 i}^{-2} \hat{e}_{i t-1}^{* 2}\right)^{-1 / 2} \sum_{i=1}^{N} \sum_{t=1}^{T} R_{11 i}^{-2}\left(\hat{e}_{i t-1}^{*} \Delta \hat{e}_{i t}^{*}\right)
\end{aligned}
$$

Group $\rho$, group $P P$ and group $A D F$ are three Group Pedroni (1999) statistics;

Group $\rho$ statistics $: \tilde{Z}_{\rho}=\sum_{i=1}^{N}\left(\sum_{t=1}^{T} \hat{e}_{i-1}^{2}\right)^{-1} \sum_{i=1}^{T}\left(\hat{e}_{i t-1} \Delta \hat{e}_{i t}-\lambda_{i}\right)$

Group PP statistics(Non Parametric) $: \tilde{Z}_{t}=\sum_{i=1}^{N}\left(\sigma^{2} \sum_{t=1}^{T} \hat{e}_{i-1}^{2}\right)^{-1 / 2} \sum_{t=1}^{T}\left(\hat{e}_{i t-1} \Delta \hat{e}_{i t}-\lambda_{i}\right)$

Group ADF statistics (Parametric) $: \tilde{Z}_{t}^{*}=\sum_{i=1}^{N}\left(s_{i}^{* 2} \sum_{t=1}^{T} \hat{e}_{i-1}^{* 2}\right)^{-1 / 2} \sum_{t=1}^{T}\left(\hat{e}_{i t-1}^{*} \Delta \hat{e}_{i t}^{*}\right)$

\subsection{Panel Autoregressive Distributed Lag Model (ARDL)}

After analyzing the existence of long run relationship next step is to estimate long run parameters. The typical methodology to establish long run relationship in panel analysis is panel Autoregressive Distributed Lag Model. It has several advantages over DOLS, FMOLS and GMM. This technique estimates long run and short time estimates simultaneously. Secondly, it resolves the issue of endogeneity by introducing lagged terms of dependent and independent variables. Thirdly, it is applicable either variables are integrated at level, first difference or mixed order. Autoregressive Distributed Lag Model is based on three different estimators for analysis of panel data. These estimators are: 
Environmental Kuznets Curve and Income Inequality: Pooled Mean Group Estimation for Asian Developing Countries

i) Mean group estimator (MG)

ii) Pooled mean group estimators (PMG)

iii) Dynamic fixed effects estimators (DFE)

\subsection{The Pooled Mean Group}

Pooled Mean Group (PMG) within ARDL framework was devised by Pesaran et al. (1999) to investigate the short run and long run parameters. The basic prerequisites for PMG estimator to be consistent ad efficient are as:

i) Error terms should not be serially correlated and this issue is resolved by introducing lag of dependent variable (p) and lag of explanatory variables (q) in error correction representation. All the explanatory variables are supposed to be truly exogenous.

ii) Long run relationship is present between dependent variables and regressors.

iii) It assumes long run estimates to be same for all countries.

The main feature of PMG estimator is that it assumes long run parameters to be same for all the countries but short run coefficients, ECM coefficient, intercepts and error variance to be different for each country.

The ARDL specification in PMG formulation is given below:

$$
y_{i t}=\sum_{j=1}^{p} \gamma_{i j} y_{t-j}+\sum_{j=0}^{q} \beta_{i j} x_{t-j}+\mu_{i}+\varepsilon_{i t}
$$

$y_{i t}$ is dependent variable such as $\mathrm{CO} 2, \mathrm{SO} 2$ emission and PM2.5 in the current study. $x_{i t-j}$ denotes explanatory variables including GDP per capita, GDP per capita square, income inequality, population density, urban population, trade openness and FDI. $\mu_{i}$ depicts fixed effect and $\varepsilon_{i t}$ is error component. The above model can be written in VECM representation as:

$$
\Delta y_{i t}=\theta_{i}\left(y_{i t-1}-\beta_{i} x_{i t-1}\right)+\sum_{j=1}^{p-1} \lambda_{i j} \Delta y_{i t-j}+\sum_{j=0}^{q-1} \delta_{i j} \Delta x_{i t-j}+\mu_{i t}+\varepsilon_{i t}
$$

$\beta_{i}$ are long-run parameters, $\theta_{i}$ shows convergence of variables towards long run equilibrium. $\lambda_{i}$ and $\delta_{i}$ denote short-run coefficients of dependent and independent 
variables respectively. The selection of suitable lag length for each country is made using SBC and AIC for both MG and PMG estimations. The sign of ECM term should be negative that will represent stable long run relationship. PMG require large $\mathrm{T}$ and $\mathrm{N}$ for consistent and efficient results. Hausman's test distinguishes between appropriateness of MG and PMG. The null hypothesis of Hausman's test is that $\mathrm{MG}$ is appropriate meaning that long run slopes are homogenous against the alternative that PMG is appropriate which depicts that long run slopes are heterogeneous. If the alternative hypothesis is accepted the PMG estimator would yield efficient results and vice versa. All the three estimators are computed by maximum likelihood estimations. PMG estimator lies in between MG and DFE as it is based on pooling and averages of estimated coefficients.

\section{Results and Discussion}

To avoid spurious results and moving towards econometric analysis, it is essential to analyze the stationary properties of data. Thus study applies Levin, Lin $\&$ Chi (LLC) and Im Pesaran \& Shin (IPS) panel unit root test to do so. The results of both tests with intercept and trend are presented in the Table 1 and 2.

Table 1: Model 1 Panel Unit Root Tests Results

\begin{tabular}{ccccc}
\hline & \multicolumn{2}{c}{ LLC } & \multicolumn{2}{c}{ IPS } \\
\cline { 2 - 5 } Variables & At Level & $\mathbf{1}^{\text {st }}$ Difference & At Level & $\mathbf{1}^{\text {st }}$ Difference \\
LnCO2 & $-10.7960^{*}$ & -13.2375 & $-6.65607^{*}$ & -15.4338 \\
LnGDPPC & 8.65440 & $-12.58044^{* *}$ & 16.0939 & $-11.0186^{*}$ \\
LnGDPPCS & 13.1895 & $-1.51614^{* *}$ & 19.7094 & $-8.80836^{* *}$ \\
INEQ & 1.35217 & $-1.13124^{* *}$ & 1.94465 & $-0.33264^{* *}$ \\
LnPD & 5.42870 & $-9.24309^{*}$ & 4.87859 & $-1.07201^{*}$ \\
UP & $-1.40996^{*}$ & -2.22364 & $-1.03413^{*}$ & -1.95335 \\
FDI & $-1.09748^{*}$ & -11.1048 & $-3.79698^{*}$ & -18.6471 \\
TO & 1.31658 & $-11.0733^{*}$ & 0.23015 & $-14.3080^{*}$ \\
\hline
\end{tabular}

Note: *** Shows $10 \%$, ** represents $5 \%$ and * indicates $1 \%$ level of significance.

Due to different time span LLC and IPS have been performed separately for model 1 and model $2 \& 3$. Both tests have almost similar findings regarding variables however, none of above variables is stationary at I(2). The findings of both LLC and IPS tests depict that some variables are stationary at I(0) and others are $\mathrm{I}(1)$ in both tables. The results further necessitate the application of cointegration test and study employs Pedroni Cointegration test to identify the existence of cointegration among variables. Pedroni test results are reported in the Table 3. 
Environmental Kuznets Curve and Income Inequality: Pooled Mean Group Estimation for Asian Developing Countries

Table 2: Model 2 and Model 3 Panel Unit Root Results

\begin{tabular}{ccccc}
\hline & \multicolumn{2}{c}{ LLC } & \multicolumn{2}{c}{ IPS } \\
\cline { 2 - 5 } Variables & At Level & $\mathbf{1}^{\text {st }}$ Difference & At Level & $\mathbf{1}^{\text {st }}$ Difference \\
LnSO2 & 1.72498 & $-6.26306^{*}$ & 2.62796 & $-8.73883^{*}$ \\
LnPM2.5 & $-20.9040^{*}$ & -15.5122 & $-5.87696^{*}$ & -7.94349 \\
LnGDPPC & 1.17171 & $-10.6654^{*}$ & 1.33628 & $-10.4682^{*}$ \\
LnGDPPCS & 2.56254 & $-9.80749^{*}$ & 1.60556 & $-9.94236^{*}$ \\
INEQ & 1.12081 & $-7.96758^{*}$ & 1.21447 & $-7.39984^{*}$ \\
Ln PD & 9.37277 & $-6.15123^{*}$ & 13.6903 & $-8.92464^{*}$ \\
UP & $-17.6046^{*}$ & -33.1149 & $-7.75302^{*}$ & -29.9695 \\
FDI & $-2.36718^{*}$ & -9.61282 & $-2.08386^{*}$ & -8.9759 \\
TO & 2.02253 & $-3.30387^{*}$ & 0.91243 & $-8.17830^{*}$ \\
\hline
\end{tabular}

Note: $* * *$ Shows $10 \%, * *$ represents $5 \%$ and $*$ indicates $1 \%$ level of significance.

Table 3: Pedroni Cointegration Results

\begin{tabular}{cccc}
\hline Models & Model 1 & Model 2 & Model 3 \\
\hline Test Statistics & t-statistic & t-statistic & t-statistic \\
Panel v-statistic & -1.558544 & -1.739901 & 0.038834 \\
& $(0.9404)$ & $(0.9591)$ & $(0.4845)$ \\
Panel rho-statistic & 1.459375 & 3.247312 & 1.143257 \\
& $(0.9278)$ & $(0.9994)$ & $(0.8735)$ \\
Panel PP-statistic & $-3.565545^{*}$ & $-1.155620^{*}$ & $-0.913976^{*}$ \\
& $(0.0002)$ & $(0.0061)$ & $(0.0014)$ \\
Panel ADF-statistic & $-4.596395^{*}$ & $-0.306038^{*} *$ & $-0.560959^{*}$ \\
& $(0.0000)$ & $(0.0202)$ & $(0.0024)$ \\
Group rho-statistic & 2.968924 & 4.263798 & 1.350153 \\
& $(0.9985)$ & $(1.0000)$ & $(0.9115)$ \\
Group PP-statistic & $-3.940041^{*}$ & $-1.434349 * *$ & $-4.020403 *$ \\
& $(0.0000)$ & $(0.0357)$ & $(0.0000)$ \\
Group ADF-statistic & $-4.246767 *$ & $-1.734757^{*} *$ & $-3.468722^{*}$ \\
& $(0.0000)$ & $(0.0414)$ & $(0.0003)$ \\
& Kao Residual Cointegration Test Results & \\
Test & t-Statistic & t-Statistic & t-Statistic \\
ADF & $-14.54847^{*}$ & $-6.138318 *$ & $-13.23463^{*}$ \\
& $(0.0000)$ & $(0.0000)$ & $(0.0000)$ \\
\hline
\end{tabular}

Note: $* * *$ Shows $10 \%$, ** represents $5 \%$ and $*$ indicates $1 \%$ level of significance. p value are shown in parentheses.

The findings of Pedroni test illuminates that majority of test statistics have rejected null hypothesis of no cointegration at $1 \%$ and $5 \%$ level of significance in 
all models so there is strong evidence of cointegration relationship. Moreover, Kao test also

Table 4: PMG Estimation Results

\begin{tabular}{|c|c|c|c|}
\hline Variables & \multicolumn{3}{|c|}{ Dependent Variables: Environment Quality } \\
\hline Variables & $\mathrm{CO} 2$ & $\mathrm{SO} 2$ & PM2.5 \\
\hline \multirow{2}{*}{ LnGDPPC } & $1.977342 *$ & $1.298677 *$ & $4.562469 * *$ \\
\hline & $(0.750053)$ & $(0.232093)$ & $(2.044403)$ \\
\hline \multirow[t]{2}{*}{ LnGDPPCS } & $-0.087424 * *$ & $-0.083520 *$ & $-0.307415^{* *}$ \\
\hline & $(0.044329)$ & $(0.015395)$ & $(0.151392)$ \\
\hline \multirow[t]{2}{*}{ INEQ } & $0.018937 * *$ & $0.012978 * *$ & $0.053081 * *$ \\
\hline & $(0.008070)$ & $(0.005991)$ & $(0.025909)$ \\
\hline \multirow[t]{2}{*}{ LnPD } & $0.168645 * * *$ & $0.439800 * *$ & $0.294724 *$ \\
\hline & $(0.101212)$ & $(0.180445)$ & $(0.110902)$ \\
\hline \multirow[t]{2}{*}{ UP } & $0.047568 *$ & 0.030569 & $0.150679 *$ \\
\hline & $(0.005317)$ & $(0.021252)$ & $(0.014263)$ \\
\hline \multirow[t]{2}{*}{ FDI } & 0.005237 & $0.095818 *$ & $0.084638 *$ \\
\hline & $(0.007386)$ & $(0.019786)$ & $(0.029489)$ \\
\hline \multirow[t]{2}{*}{ TO } & $0.003100 *$ & $0.010101 *$ & $0.018386 *$ \\
\hline & $(0.000938)$ & $(0.001709)$ & $(0.004079)$ \\
\hline \multicolumn{4}{|c|}{ Short Run Results } \\
\hline \multirow[t]{2}{*}{$\triangle \mathrm{LnGDPPC}$} & $1.123396 * * *$ & $0.921310 * *$ & $2.075240 * *$ \\
\hline & $(0.596012)$ & $(0.460199)$ & $(1.11150)$ \\
\hline \multirow[t]{2}{*}{$\triangle \mathrm{LnGDPPCS}$} & 0.263629 & -0.057965 & -0.119823 \\
\hline & $(0.376988)$ & $(0.046209)$ & $(0.137902)$ \\
\hline \multirow[t]{2}{*}{$\triangle \mathrm{INEQ}$} & $0.045723 * *$ & 0.032586 & $0.014885 * * *$ \\
\hline & $(0.021142)$ & $(0.052248)$ & $(0.007656)$ \\
\hline \multirow[t]{2}{*}{$\Delta \mathrm{LnPD}$} & $2.673201 * *$ & $5.506705^{*}$ & $1.413826^{* *}$ \\
\hline & $(1.079724)$ & $(2.077080)$ & $(0.613764)$ \\
\hline \multirow[t]{2}{*}{$\Delta \mathrm{UP}$} & $0.187367 *$ & 0.028397 & 0.116830 \\
\hline & $(0.096421)$ & $(0.094027)$ & $(0.075779)$ \\
\hline \multirow[t]{2}{*}{$\Delta \mathrm{FDI}$} & 0.006344 & 0.002240 & -0.003129 \\
\hline & $(0.006781)$ & $(0.007717)$ & $(0.003193)$ \\
\hline \multirow[t]{2}{*}{$\Delta \mathrm{TO}$} & 0.000766 & $0.001175 * *$ & 0.000600 \\
\hline & $(0.000721)$ & $(0.000579)$ & $(0.000553)$ \\
\hline \multirow[t]{2}{*}{$\mathrm{ECT}(\mathrm{t}-1)$} & $-0.241615^{*}$ & $-0.151576^{*}$ & $-0.349079 *$ \\
\hline & $(0.076476)$ & $(0.055868)$ & $(0.097902)$ \\
\hline
\end{tabular}

Note: * shows $1 \% * *$ and $* * *$ represents $5 \%$ and $10 \%$ significance level respectively. Standard Errors are shown in parentheses.

rejects the null hypothesis of no cointegration as value of t-statistics of ADF test is statistically significant for all models. When long run relationship is identified the 
study adopts panel ARDL to obtain long run estimates. First of all, Haumans' test is performed whose value is 13.776 with probability 0.01 which is less than 0.05 thus rejects the null hypothesis that MG is preferable over PMG estimator. So PMG estimation technique has been adopted to obtain empirical estimates and it is more appropriate to our analysis because developing countries have similar demographic and economic conditions. The choice of lag ARDL $(1,1,1,1,1,1,1,1)$ has been made by considering SBC criterion on the basis of smallest value. The results of PMG estimation for all regression models are stated in the Table 4.

The PMG results for model 1 indicate that per capita GDP is positively attached with $\mathrm{CO}_{2}$ emission and per capita GDP square has negative effect on $\mathrm{CO}_{2}$ emission. These findings are statistically significant at $1 \%$ significant at $5 \%$ when $\mathrm{CO}_{2}$ emission is used as environmental quality indicator. These results confirm the presence of EKC for developing Asian countries in long run. Hailemariam et al. (2019) and Drabu (2011) have found identical outcomes. Short run findings reveal no evidence of EKC and same has been found by Audi and Ali (2018). The main interest of the study is effect of income inequality that is positively attached with environmental degradation. Masud et al. (2018) and Drabu (2011) have identical results for growing countries. Demographic indicators are positively related with environmental degradation in case of Asian developing economies. The rise in population density and urban population raises $\mathrm{CO}_{2}$ emission. Similar results have been traced in earlier work of Jun et al. (2011) and Omotor (2016). The coefficient of FDI carries positive sign but is insignificant. The effect of trade openness on $\mathrm{CO}_{2}$ emission is also positive and significant. Mahmood (2018) et al. and Tjoek and Wu (2018) also found positive impact of trade openness and FDI on environment quality for Asian countries. In the short run, trade openness and FDI exert positive but statistically insignificant impact on $\mathrm{CO}_{2}$ emission.

The assessment of PMG results for model 2 depicts the presence of EKC in case of $\mathrm{SO}_{2}$ emission. These findings are similar with the work of Rawashdeh et al. (2014), Hao et al. (2016) and Omotor (2016) and Torras and Boyce (1998) for developing countries. However, EKC does not found in the short run for $\mathrm{SO}_{2}$ emission which is consistent with Asongu et al. (2015). The key variable is also positively related with $\mathrm{SO}_{2}$ emission that indicate higher the income inequality more will be environmental damage. This is somewhat similar with Boyce (1994) and Torras and Boyce (1998). The estimated coefficients of population density, urban population indicates that rise in demographic variables accelerate $\mathrm{SO}_{2}$ emission significantly. Trade openness and foreign direct investment are positively correlated with $\mathrm{SO}_{2}$. Tjoek and $\mathrm{Wu}$ (2018) and Omotor (2016) found positive association between trade openness and $\mathrm{SO}_{2}$ emission. Zhu et al. (2017) established 
positive effect of FDI on $\mathrm{SO}_{2}$ emission. However, the coefficient of FDI is negatively associated with environment quality in short run. The study found direct association between population density and $\mathrm{SO}_{2}$ emission both in long and short run. This is somewhat similar with Zhu et al. (2017). The effect of urban population is positive but insignificant in long run. Similarly, income inequality, urban population and FDI have insignificant impact on $\mathrm{SO}_{2}$ emission in short run.

There is positive association between per capita growth and exposure to PM2.5 while GDP per capita square is negatively associated with PM2.5. It indicates the incidence of EKC in the long run. These finding are significant at 5\% and similar with Orubu et al. (2009) and Stern and Zha (2016). There is no evidence of EKC in the short run in case of PM2.5. The income inequality has positive and significant effect on environmental degradation at 5\% significance level showing more deterioration in environment quality is attached with rising differences in income. Marsiliani and Renstrom (2000) have same findings about unequal income distribution effect. There is positive and significant effect of population density, urban population on PM2.5 indicating that demographic variables exacerbate deterioration of environment and Orubu et al. (2009) obtained same results. Trade openness and FDI also exert positive impact on environment quality variable. Urban population, trade openness and FDI have no impact on PM2.5 in short run. The coefficient of ECT is negative and statistically significant for all models showing speed of adjustment towards long run equilibrium.

\section{Conclusion and Discussion}

The study attempts to explore the relationship between environmental quality and economic growth along with role of income inequality within EKC framework by using balanced panel data for developing Asian countries. Three models have been estimated by using $\mathrm{CO}_{2}, \mathrm{SO}_{2}$ emission and PM2.5 as environmental quality indicators. PMG estimation within ARDL framework recommended by Hausman's test has been employed for empirical analysis. Empirical findings of PMG estimator validate the existence of $\mathrm{EKC}$ for $\mathrm{CO}_{2}, \mathrm{SO}_{2}$ emission and PM2.5 in the long run. However, EKC does not hold in short run for developing Asian countries. The existence of EKC in developing countries demonstrates that economic expansion requires more energy which is mostly obtained from the combustion of fossil fuel for industries and transportation that results in higher $\mathrm{CO}_{2}$ emission in developing countries. Existence of polluted industries and old technology are also reasons of EKC existence. Moreover, these economies major focus is more on growth rather than environment. The results compel governments of developing economies to focus on the use of clean energy 
and carbon tax in order to save environment from $\mathrm{CO}_{2}$ emission. Another reason behind positive effect may be overuse of natural resources by the rich community as well as poor as they have no other source available for their survival. Similarly, the people of developing countries do not afford clean fuel and are dependent on biomass fuel especially for cooking and heating which is also major contributor of $\mathrm{CO}_{2}$ emission in air.

There are various rationales for the incidence of $\mathrm{EKC}$ in case of $\mathrm{SO}_{2}$ emission. The rising trend of $\mathrm{SO}_{2}$ emission illustrates that these countries are growing economies and dependent on coal especially in power generation sector to fulfill the energy demand of industrial sector and other sectors of the economy. Industries, vehicular emission, combustion of solid and biomass fuel are also the main sources of $\mathrm{SO}_{2}$ emission in developing nations. Similarly sources of Particulate matter includes combustion, dust and automobile emission that are rising overtime leading to rise in particulate concentrations. These findings insist governments of developing nations to explore renewable and clean energy resources and efficient coal technology to save the environment. Overall, industrial expansion, advance farming and intensification of agriculture sector are also contributing to degradation of environment.

Furthermore, income inequality exerts positive and significant influence on all environment quality indicators. The reason of positive effect may be overuse of natural resources by the poor as they have no other source of livelihood for their survival. The positive association between rising inequality and pollution indicators indicate that poor people and unequal societies of developing nations do not consider environment as an essential commodity due to lack of awareness and sound regulations about environmental protection. These findings suggest governments to promote equal societies to conserve the environment.

Industrial expansion and FDI development are associated with intensive use of energy obtained from oil, gas, fossil fuels and other natural resources which are considered basic inputs of industrial sector therefore positive association holds between FDI and environment quality measures. Trade openness has also not favourable impact on environment. No doubt trade is driver of any economy but results show that trade expansion is attached with pollution through production process. The positive effect of trade openness and FDI implies that clean production technology is not being adopted in developing economies. Results suggest that developing countries should adopt environment friendly production technologies. Less developed economies should improve economic structure through modernization and ensure environmental regulation for sustainable growth. The 
findings suggest that tree plantation campaign and restoring the forests are most appropriate tool to control greenhouse gas emission. Moreover government should construct industrial zones outside the city areas. It will also be easy for the enforcement of polices about reducing pollution. Government should promote environment friendly transport like electric vehicles and lead battery techniques

Population growth is supportive for economic upturn but it becomes danger when increases from threshold limit. On the same lines, lack of employment opportunities, inadequate infrastructure, recreational facilities and other social privileged benefits are pushing people towards urban areas and this tendency has risen since few decades. The growing population and unplanned expansion of cities require more environmental resources that will put pressure on resources through the overuse of resources. It also creates mismatch between demand and supply of natural and environmental resources resulting in deterioration of environment in the form of air, water and land pollution. Therefore, coefficients of population density and urbanization carry positive sign in case of all pollutants meaning that rising population escalate more degradation. The issue of urbanization should be resolved through proper planning \& local community involvement. Government should focus on creation of jobs and poverty reduction strategies in rural areas to control rising population in urban areas. 
Environmental Kuznets Curve and Income Inequality: Pooled Mean Group Estimation for Asian Developing Countries

\section{References}

Al Sayed, A. R., \& Sek, S. K. (2013). Environmental Kuznets Curve: Evidences from. Applied Mathematical Sciences, 7(22), 1081-1092.

Andreoni, J.,\&Levinson, A. (2001). The simple analytics of the environmental Kuznets curve. Journal of Public Economics, 80, 269-286.

Asongu, S., El Montasser, G., \& Toumi, H. (2016). Testing the relationships between energy consumption, $\mathrm{CO} 2$ emissions, and economic growth in 24 African countries: a panel ARDL approach. Environmental Science and Pollution Research, 23(7), 6563-6573.

Asteriou, D., \& Hall, G. S. (2007). Applied Econometrics: a Modern Approach Palgrave Macmillan. New York.

Borghesi, S. (2000). Inequality, Growth and the Environment: A Steady-State Analysis of the Kuznets Curve and the Environmental Kuznets Curve. SSRN Journal,110(95),353-377.

Boyce J.K., (1994). Inequality as a cause of environmental degradation, Ecological Economics, 5(11),169-178

Boyce, J. K \& Vornovytskyy, M.S (2010). Economic inequality and environmental quality: evidence of pollution shifting in Russia. PERI Working Papers, 189.

Clément, M., \& Meunié, A. (2008). Economic Growth, inequality and environment quality: An empirical analysis applied to developing and transition countries. Cahiers du GREThA, 13.

Demir, C., Cergibozan, R., \& Gök, A. (2019). Income inequality and CO2 emissions: Empirical evidence from Turkey. Energy \& Environment, 30(3), 444-461.

Engle, R. F., \& Granger, C. W. (1987). Co-integration and error correction: representation, estimation, and testing. Econometrica: journal of the Econometric Society, 251-276.

Grossman, G. M. \& Krueger, A. B. (1991). Environmental impacts of a North American Free Trade Agreement. NBER Working Papers, 3914.

Grossman, G.M, and Krueger. A. B. (1995). "Economic Growth and the Environment." The Quarterly Journal of Economics, 110(2): 353-377. 
Hailemariam, A., Dzhumashev, R., \& Shahbaz, M. (2019). Carbon emissions, income inequality and economic development. Empirical Economics, 1-21.

Hao, Y., Chen, H., \& Zhang, Q. (2016). Will income inequality affect environmental quality? Analysis based on China's provincial panel data. Ecological indicators, 67, 533-542.

Im, K. S., Pesaran, M. H., \& Shin, Y. (2003). Testing for unit roots in heterogeneous panels. Journal of econometrics, 115(1), 53-74.

Jun, Y., Zhong-kui, Y., \& Peng-fei, S. (2011). Income distribution, human capital and environmental quality: empirical study in China. Energy Procedia, 5, 1689-1696.

Kao, C. (1999). Spurious regression and residual-based tests for cointegration in panel data. Journal of Econometrics,90(1), 1-44.

Kuznets, Simon (1955) "Economic Growth and Income Inequality," American Economic Review. 49,1-28.

Levin, A., C.F. Lin and C.S.J. Chu (2002) "Unit root tests in panel data: asymptotic and finite-sample properties", Journal of Econometrics, 108, 1-24.

Mahmood, H., Furqan, M., \& Bagais, O. (2019). Environmental accounting of financial development and foreign investment: Spatial analyses of East Asia. Sustainability, 11(1), 13.

Marsiliani, L., \& Renstrom, T. I. (2000). Inequality, environmental protection and growth.

Masud, M. M., Kari, F. B., Banna, H., \& Saifullah, M. K. (2018). Does income inequality affect environmental sustainability? Evidence from the ASEAN5. Journal of the Asia Pacific Economy, 23(2), 213-228.

Omotor, D. G. (2017). Economic growth and emissions: testing the environmental kuznets curve hypothesis for ECOWAS countries. West African Journal of Monetary and Economic Integration, 17(2), 25-56.

Orubu, C. O., Omotor, D. G., Awopegba, P. O., \& Ababa, A. (2009). Economic growth and environmental quality: searching for environmental kuznets curves in Africa. Paper Presented at CSAE Conference, University of Oxford, UK. March $22-242009$ 
Environmental Kuznets Curve and Income Inequality: Pooled Mean Group Estimation for Asian Developing Countries

Ota, T.(2017). Economic growth, income inequality and environment: assessing the applicability of the Kuznets hypotheses to Asia. Palgrave Communications, 3, 17069.

Pedroni, P. (1999). Critical values for cointegration tests in heterogeneous panels with multiple regressors. Oxford Bulletin of Economics and statistics, 61(S1), 653-670.

Pedroni, P. (2004). Panel cointegration: asymptotic and finite sample properties of pooled time series tests with an application to the PPP hypothesis. Economic Theory 20(3), 597-625

Pedroni, P. (2004). Panel cointegration: asymptotic and finite sample properties of pooled time series tests with an application to the PPP hypothesis. Econometric theory, 20(3), 597-625.

Pedroni, P. (2004). Panel cointegration: asymptotic and finite sample properties of pooled time series tests with an application to the PPP hypothesis. Econometric theory, 20(3), 597-625.

Perman, R., \& Stern, D. I. (2003). Evidence from panel unit root and cointegration tests that the environmental Kuznets curve does not exist. Australian Journal of Agricultural and Resource Economics, 47(3), 325-347.

Pesaran, M. H., Shin, Y., \& Smith, R. P. (1999). Pooled mean group estimation of dynamic heterogeneous panels. Journal of the American Statistical Association, 94(446), 621-634.

Ravallion, M., Heil, M., and Jalan, J. (2000). Carbon emissions and income inequality. Oxford Economic papers, 52(4), 651-669.

Scruggs, L. A. (1998). Political and economic inequality and the environment. Ecological economics, 26(3), 259-275.

Selden, T. M., \& Song, D. (1994). Environmental quality and development: are there a Kuznets curve for air pollution emissions? Journal of Environmental Economics and management, 27(2), 147-162.

Serrano, A. L. M., Sobreiro, V. A., \& Neto, J. C. (2015). Income inequality and environmental degradation: estimates with panel data in Brazilian states. Latin American Journal of Management for Sustainable Development, 2(1), 36-46. 
Shafik, N., \& Bandyopadhyay, S. (1992). Economic growth and environmental quality: time-series and cross-country evidence (Vol. 904). World Bank Publications.

Stern, D. I., \& Zha, D. (2016). Economic growth and particulate pollution concentrations in China. Environmental Economics and Policy Studies, 18(3), 327-338.

Taguchi, H. (2013). The environmental Kuznets curve in Asia: The case of sulphur and carbon emissions. Asia-Pacific Development Journal, 19(2), 77-92.

Tjoek, P. W. (2018). Exploring the environmental Kuznets curve for CO2 and SO2 for Southeast Asia in the 21st century context. Environmental Economics, 9(1), 7.

Torras, M. \& Boyce, J. K. (1998). Income, inequality, and pollution: a reassessment of the environmental Kuznets curve. Ecological Economics, 25, 147-160.

World Commission on Environment and Development (1987). Our common future. Oxford: Oxford University Press.

Xie, Y., Dai, H., Zhang, Y., Wu, Y., Hanaoka, T., \& Masui, T. (2019). Comparison of health and economic impacts of PM2.5 and ozone pollution in China. Environment international, 130, 104881.

Zhu, L., Gan, Q., Liu, Y., \& Yan, Z. (2017). The impact of foreign direct investment on SO2 emissions in the Beijing-Tianjin-Hebei region: A spatial econometric analysis. Journal of cleaner production, 166, 189-196. 
Environmental Kuznets Curve and Income Inequality: Pooled Mean Group Estimation for Asian Developing Countries

\section{Appendix A}

\section{List of Countries:}

Bangladesh, Egypt, India, Iran, Indonesia, Malaysia, Pakistan, Sri Lanka, Nepal, Jordon, Cambodia, Nepal, Philippines, Thailand, Maldives, Vietnam

\section{Appendix B}

Descriptive Statistics for Model 1

\begin{tabular}{lcccccccc}
\hline & CO2 & GDPPC & GDPPCS & INEQ & PD & UP & FDI & TO \\
\hline Mean & 1.572365 & 2494.985 & 12393783 & 39.94200 & 221.2274 & 36.49206 & 1.955026 & 72.42180 \\
Median & 0.964500 & 1656.283 & 2743300. & 39.75000 & 111.8281 & 31.91450 & 0.988664 & 57.68444 \\
Maximum & 8.492000 & 12592.67 & $1.59 \mathrm{E}+08$ & 50.30000 & 1391.640 & 90.50600 & 23.53737 & 220.4074 \\
Minimum & 0.000000 & 315.9296 & 99811.53 & 30.40000 & 18.97411 & 4.399000 & -6.0080 & 8.320137 \\
Std. Dev. & 1.734070 & 2485.479 & 24315406 & 4.871768 & 278.4962 & 19.35239 & 2.677938 & 46.13145 \\
Skewness & 1.877924 & 1.694114 & 3.210719 & 0.255603 & 2.327467 & 0.586204 & 2.527049 & 1.084872 \\
Kurtosis & 6.573733 & 5.670976 & 14.22568 & 2.376532 & 7.839312 & 2.522899 & 13.04811 & 3.318771 \\
Sum Sq. Dev. & 2113.920 & $4.34 \mathrm{E}+09$ & $4.16 \mathrm{E}+17$ & 16685.09 & 54524759 & 263284.2 & 5041.462 & 1496062. \\
Observations & 704 & 704 & 704 & 704 & 704 & 704 & 704 & 704 \\
\hline
\end{tabular}

Descriptive Statistics for Model 2

\begin{tabular}{lcccccccc}
\hline & SO2 & GDPPC & GDPPCS & INEQ & PD & UP & FDI & TO \\
\hline Mean & 575.6558 & 5943.754 & 65255546 & 39.938 & 207.2509 & 35.0657 & 1.78883 & 70.8913 \\
Median & 195.0866 & 4084.000 & 16679105 & 39.700 & 106.1323 & 29.9200 & 0.84331 & 57.7927 \\
Maximum & 9452.590 & 29546.00 & $8.73 \mathrm{E}+08$ & 50.300 & 1223.333 & 86.0880 & 23.5373 & 220.407 \\
Minimum & 0.200255 & 737.0000 & 543169.0 & 30.400 & 18.97411 & 4.39900 & 6.008030 & 8.32013 \\
Std. Dev. & 1165.848 & 5475.093 & $1.25 \mathrm{E}+08$ & 4.8784 & 256.4924 & 18.6481 & 2.60085 & 46.0135 \\
Skewness & 4.124628 & 1.724775 & 3.716666 & 0.2023 & 2.249314 & 0.57570 & 2.76667 & 1.16067 \\
Kurtosis & 22.62872 & 6.333038 & 19.21081 & 2.3840 & 7.408483 & 2.46580 & 15.4092 & 3.58629 \\
S. Sq. Dev. & $8.22 \mathrm{E}+08$ & $1.82 \mathrm{E}+10$ & $9.56 \mathrm{E}+18$ & 14446. & 3993353 & 211086. & 4106.00 & 1285166 \\
Obs. & 608 & 608 & 608 & 608 & 608 & 608 & 608 & 608 \\
\hline
\end{tabular}

\section{Descriptive Statistics for Model 3}

\begin{tabular}{lcccccccc}
\hline & PM2.5 & GDPPC & GDPPCS & INEQ & PD & UP & FDI & TO \\
\hline Mean & 739.0680 & 5943.754 & 6525554 & 39.9383 & 207.2509 & 35.0657 & 1.78883 & 70.8913 \\
Median & 168.4956 & 4084.000 & 16679105 & 39.70000 & 106.1323 & 29.92000 & 0.843317 & 57.79279 \\
Maximum & 8870.921 & 29546.00 & $8.73 \mathrm{E}+08$ & 50.30000 & 1223.333 & 86.08800 & 23.53737 & 220.4074 \\
Minimum & 0.032026 & 737.0000 & 543169.0 & 30.40000 & 18.97411 & 4.399000 & 6.008030 & 8.320137 \\
Std. Dev. & 1498.282 & 5475.093 & $1.25 \mathrm{E}+08$ & 4.878424 & 256.4924 & 18.64816 & 2.600850 & 46.01350 \\
Skewness & 3.264461 & 1.724775 & 3.716666 & 0.202336 & 2.249314 & 0.575701 & 2.766679 & 1.160673 \\
Kurtosis & 13.51206 & 6.333038 & 19.21081 & 2.384029 & 7.408483 & 2.465802 & 15.40925 & 3.586294 \\
S. Sq. Dev. & $1.36 \mathrm{E}+09$ & $1.82 \mathrm{E}+10$ & $9.56 \mathrm{E}+18$ & 14446.01 & 39933536 & 211086.7 & 4106.003 & 1285166. \\
Obs. & 608 & 608 & 608 & 608 & 608 & 608 & 608 & 608 \\
\hline
\end{tabular}

\section{Appendix C}

\section{Limitations and Future Perspective}

The study can be further extended by separated analysis of indoor and outdoor air pollutants. Moreover, other pollutants which are harmful for human health like PM10 can be considered for better analysis. 